OPEN ACCESS

Edited by:

Renjie Chai,

Southeast University, China

Reviewed by:

Zheng-Quan Tang,

Anhui University, China

Jiaqi Pang,

Sun Yat-sen University, China

${ }^{*}$ Correspondence:

Xiujie Gao

xjgao@ustc.edu

$\mathrm{Bo} \mathrm{Cui}$

iamcuib@sina.com

tThese authors have contributed equally to this work and share first authorship

Specialty section:

This article was submitted to Molecular and Cellular Pathology,

a section of the journal

Frontiers in Cell and Developmental

Biology

Received: 05 June 2021

Accepted: 14 July 2021

Published: 04 August 2021

Citation:

Ma $K$, Zhang $A$, She $X$, Yang $H$, Wang $K$, Zhu Y, Gao $X$ and Cui $B$

(2021) Disruption of Glutamate

Release and Uptake-Related Protein

Expression After Noise-Induced

Synaptopathy in the Cochlea.

Front. Cell Dev. Biol. 9:720902.

doi: 10.3389/fcell.2021.720902

\section{Disruption of Glutamate Release and Uptake-Related Protein Expression After Noise-Induced Synaptopathy in the Cochlea}

\author{
Kefeng $\mathrm{Ma}^{1+}$, Anran Zhang ${ }^{1,2 t}$, Xiaojun She ${ }^{1}$, Honglian Yang ${ }^{1}$, Kun Wang ${ }^{1}$, Yingwen Zhu' \\ Xiujie $\mathrm{Gao}^{1 *}$ and Bo Cui ${ }^{1,2 *}$ \\ ${ }^{1}$ Tianjin Institute of Environmental and Operational Medicine, Tianjin, China, ${ }^{2}$ Shandong Academy of Occupational Health \\ and Occupational Medicine, Shandong First Medical University \& Shandong Academy of Medical Sciences, Jinan, China
}

High-intensity noise can cause permanent hearing loss; however, short-duration medium-intensity noise only induces a temporary threshold shift (TTS) and damages synapses formed by inner hair cells (IHCs) and spiral ganglion nerves. Synaptopathy is generally thought to be caused by glutamate excitotoxicity. In this study, we investigated the expression levels of vesicle transporter protein 3 (Vglut3), responsible for the release of glutamate; glutamate/aspartate transporter protein (GLAST), responsible for the uptake of glutamate; and $\mathrm{Na}^{+} / \mathrm{K}^{+}$-ATPase $\alpha 1$ coupled with GLAST, in the process of synaptopathy in the cochlea. The results of the auditory brainstem response (ABR) and CtBP2 immunofluorescence revealed that synaptopathy was induced on day 30 after $100 \mathrm{~dB}$ SPL noise exposure in C57BL/6J mice. We found that GLAST and $\mathrm{Na}^{+} / \mathrm{K}^{+}$-ATPase $\alpha 1$ were co-localized in the cochlea, mainly in the stria vascularis, spiral ligament, and spiral ganglion cells. Furthermore, Vglut3, GLAST, and $\mathrm{Na}^{+} / \mathrm{K}^{+}$ATPase $\alpha 1$ expression were disrupted after noise exposure. These results indicate that disruption of glutamate release and uptake-related protein expression may exacerbate the occurrence of synaptopathy.

Keywords: noise, synaptopathy, Vglut3, GLAST, $\mathrm{Na}^{+} / \mathrm{K}^{+}$-ATPase $\alpha 1$, glutamate excitotoxicity

\section{INTRODUCTION}

High-level noise, which can cause sensorineural hearing loss accompanied by permanent threshold shift, has become a major threat to human health. Short-duration medium-intensity noise (e.g., 98, 100, $106 \mathrm{~dB}$ SPL, $2 \mathrm{~h}$ ), which only causes a temporary threshold shift (TTS), is distinguished from high-level noise exposure (Furman et al., 2013; Liberman et al., 2015; Bakay et al., 2018; Fernandez et al., 2020; Wei et al., 2020). In the inner ear, the mechanical vibration of sound wave was transformed into the electric signals by cochlear hair cells (Wang et al., 2017; Liu Y. et al., 2019; Qi et al., 2019, 2020; Zhang Y. et al., 2020); while spiral ganglion neurons mainly function as the neural auditory transduction cells (Sun et al., 2016; Guo et al., 2019, 2021; Liu W. et al., 2019b; Zhao et al., 2019). Noise induced hearing loss includes damage of cochlear hair cells (Liu et al., 2016; He et al., 2017, 2021; Zhou et al., 2020; Cheng et al., 2021; Fu et al., 2021), cochlear supporting cells (Lu et al., 2017; Cheng et al., 2019; Tan et al., 2019; Zhang S. et al., 2019, 2020; Zhang Y. et al., 2020; 
Chen et al., 2021), spiral ganglion neurons (Guo et al., 2016, 2020, 2021; Sun et al., 2016; Liu et al., 2021) and ribbon synaptopathy (Furman et al., 2013; Shi et al., 2013; Kujawa and Liberman, 2015; Liberman et al., 2015; Bakay et al., 2018; Fernandez et al., 2020; Kohrman et al., 2020; Tserga et al., 2020a; Wei et al., 2020; Song et al., 2021). It has been reported that the wave I amplitude of the auditory brainstem response (ABR) is permanently reduced and ribbon synapses between inner hair cells (IHCs) and spiral ganglion nerves are damaged after exposure to short-duration medium intensity noise (Liberman et al., 2015; Fernandez et al., 2020; Wei et al., 2020). Glutamate excitotoxicity is known to be a major factor in the damage to ribbon synapses (Kurabi et al., 2017; Sebe et al., 2017; Hu et al., 2020), but it is unknown how glutamate-associated proteins are altered after noise exposure.

Vesicle transporter protein 3 (Vglut3), encoded by the SLC17A8 gene, is important for the development and maturation of the inner ear (Obholzer et al., 2008; Ruel et al., 2008; Kim et al., 2019). Within IHCs, Vglut3 facilitates the packaging of glutamate into vesicles which is subsequently secreted into the postsynaptic membrane during exocytosis, to transduce acoustic signals into neural signals. Disrupted expression or deletion of Vglut3 can lead to tinnitus (Zhang W. et al, 2020) and deafness (Ruel et al., 2008; Seal et al., 2008; Akil et al., 2012); previous studies have suggested that knocking out the Vglut3 allele results in decreased ribbon synapse density and the number of spiral ganglion nerves (Kim et al., 2019). Moreover, ototoxic drugs (Zhang Y. et al., 2020) and aging (Peng et al., 2013) can also affect the expression of Vglut3.

Glutamate/aspartate transporter protein (GLAST) is widely expressed in the central and peripheral nervous systems (CNS and PNS, respectively), and is mainly expressed in the pillar cells (PCs) surrounding IHCs, the main site of glutamate uptake in the inner ear (Glowatzki et al., 2006). Hakuba et al. (2000) found that cochlear glutamate levels were much higher in GLAST ${ }^{-/-}$ animals compared to wild-type animals, which may result from glutamate uptake dysfunction. Glutamate uptake through the GLAST is dependent on the $\mathrm{Na}^{+}$concentration gradient, which is primarily maintained by $\mathrm{Na}^{+} / \mathrm{K}^{+}$-ATPase (Zhang et al., 2016). $\mathrm{Na}^{+} / \mathrm{K}^{+}$-ATPase consists of $\alpha, \beta$, and $\gamma$ subunits, which are further divided into $\alpha 1, \alpha 2$, and $\alpha 3$ subunits. CNS studies have shown that GLAST interacts with $\mathrm{Na}^{+} / \mathrm{K}^{+}$-ATPase, especially through the $\alpha 1$ subunit to co-uptake extracellular glutamate to protect neurons from excitotoxic injury (Bauer et al., 2012; Zhang et al., 2016). It is unclear whether GLAST interacts with $\mathrm{Na}^{+} / \mathrm{K}^{+}$-ATPase $\alpha 1$ in the cochlea.

A cycle consisting of Vglut3 and GLAST maintains low concentrations of glutamate in the cochlea. Excitotoxicity may occur when this cycle is disrupted. Therefore, we wanted to study how Vglut3, GLAST, and $\mathrm{Na}^{+} / \mathrm{K}^{+}$-ATPase $\alpha 1$ changed after ribbon synaptopathy. First, we investigated whether GLAST interacts with $\mathrm{Na}^{+} / \mathrm{K}^{+}$-ATPase $\alpha 1$ in the inner ear. Second, we constructed a ribbon synaptopathy model using $100 \mathrm{~dB}$ SPL white noise, and then measured the expression of Vglut3, GLAST, and $\mathrm{Na}^{+} / \mathrm{K}^{+}$-ATPase $\alpha 1$ at four different time points ( $2 \mathrm{~h}, 1$ day, 7 days, and 30 days), after exposure to noise.

\section{MATERIALS AND METHODS}

\section{Animals and Groups}

Six-week-old male C57BL/6J mice $(N=55)$ were purchased from Vital River (Beijing, China). The animals were housed in a $12 \mathrm{~h}$ light/dark cycle for 1 week in an animal laboratory room, where the ambient noise was maintained below $50 \mathrm{~dB}$ SPL, and food and water were provided ad libitum. Fifteen mice were used for immunoprecipitation experiments before noise exposure, and the remaining 40 mice were divided into two groups. Ten mice were included in the control group (Ctr) without noise exposure; one mouse died due to an overdose of anesthetic injection during the ABR measurement. Thirty mice were included in the noise exposure group. $\mathrm{ABR}$ and immunofluorescence were detected on day 1 ( $1 \mathrm{~d})$, day 7 ( $7 \mathrm{~d}$ ), and day 30 (30 d) after noise exposure. All experiments were approved by the ethics committee of the Tianjin Institute of Environmental and Operational Medicine.

\section{Noise Exposure}

Mice were placed in a small cage woven with wire and placed under an amplifier (IBO, BA-215, China) at a distance of $10 \mathrm{~cm}$ from the mouse's ears. Mice were exposed to a $100 \mathrm{~dB}$ SPL white noise stimulus for $2 \mathrm{~h}$ produced by a sound generator (SKC, GZ009, China). The sound intensity was calibrated with a sound level meter (BSWA, 308, China) at the mouse's ear position, from different directions. The average noise level was $100 \pm 1.9 \mathrm{~dB}$ SPL.

\section{ABR Detection}

Auditory brainstem response was measured in an electroacoustic shielded room before noise exposure and on days 1,7 , and 30 after noise exposure. Mice were anesthetized using ketamine $(100 \mathrm{mg} / \mathrm{kg})$ and thiazide $(3 \mathrm{mg} / \mathrm{kg})$, and the recording needle was inserted into the $\mathrm{Fz}$ point of the head, the reference needle was placed in the mastoid of both ears, and the grounding needle was inserted into the skin of the forepaw. ABR waveforms were recorded at $4,8,12$, and $16 \mathrm{kHz}$ pure-tone $(3,000 \mu \mathrm{s})$ stimulations. Sound intensity was decreased in $10 \mathrm{~dB}$ steps at high levels of stimulation and in $5 \mathrm{~dB}$ steps near the hearing threshold. Because wave II was easily recognized, the lowest stimulus intensity of wave II was used as the hearing threshold, and was repeated it three times to confirm the threshold intensity. A wave I amplitude of $90 \mathrm{~dB}$ was detected at each frequency.

\section{Immunofluorescence}

Mice were anesthetized with ketamine $(100 \mathrm{mg} / \mathrm{kg})$ and thiazide $(3 \mathrm{mg} / \mathrm{kg}$ ) and the cochleae were carefully removed and fixed with $4 \%$ paraformaldehyde (PFA). Briefly, the muscle tissue was carefully removed under a body microscope (Olympus, SZX7, Japan), and a hole was drilled at the top of the cochlea. PFA was slowly injected into the cochlea from the round window, with a syringe until the top of cochlea flowed clear liquid; the cochleae were then fixed overnight at $4^{\circ} \mathrm{C}$ in $4 \%$ PFA. The fixed cochlea was placed in $10 \%$ ethylene diamine tetra-acetic acid at room temperature overnight. For whole-mount staining, cochlear basilar membranes were carefully isolated and rinsed three times with Phosphate Buffered Saline (PBS). For frozen sections, 
cochleae were rinsed three times with PBS and dehydrated overnight in $30 \%$ sucrose. Then, cochleae were cut into $20 \mu \mathrm{m}$ sections after incubation in embedding agent for 3 days. Tissues were incubated in PBS containing 1\% Triton-X 100 for $30 \mathrm{~min}$ at room temperature, followed by incubation with PBS containing $0.5 \%$ Triton-X 100 and 5\% BSA for $1 \mathrm{~h}$ at room temperature. Rabbit anti-CtBP2 (1:100; Bioworld, BS2287), rabbit anti-GLAST (1:1,000, Abcam, Ab416), and mouse anti- $\mathrm{Na}^{+} / \mathrm{K}^{+}$-ATPase $\alpha 1$ (1:500, Millipore, \#05-369) were applied overnight or for $2 \mathrm{~h}$ at room temperature. Tissues were rinsed three times for $10 \mathrm{~min}$ each with PBS containing 1\% Triton-X 100. Tissue sections were incubated in secondary antibodies conjugated with dylight 488 (1:500, Bioworld, BS10015) or dylight 549 (1:500, Bioworld, $\mathrm{BS} 10023)$, for $1 \mathrm{~h}$ at room temperature. Tissues were rinsed three times for 10 min each with PBS containing $1 \%$ Triton-X 100. The tissues were mounted on glass slides after nuclei staining.

\section{Confocal and Fluorescence Microscopy}

For whole-mount staining, tissues were photographed with a $63 \times$ oil objective using $546 \mathrm{~nm}$ wave with a laser confocal microscope (Leica, SP8, Germany). Meanwhile, the field of view was 1.8 digital zoom. All photographs were taken in $0.5 \mu \mathrm{m}$ steps with equal laser intensity and exposure time. For frozen sections, photographs were taken under a normal fluorescence microscope (Olympus BX51, Japan). Panoramic and local photographs were taken under $20 \times$ and $100 \times$ objectives, respectively, with equal fluorescence intensity and exposure time.

\section{Immunoprecipitation}

The basilar membrane, spiral ligament, and osseous spiral lamina, which were removed from the ear unexposed to noise, were placed in IP lysate $(60 \mu \mathrm{L}$, containing $1 \%$ inhibitor cocktail) on ice. Tissues were homogenized with a pestle and lysed on ice for $30 \mathrm{~min}$. The supernatant (approximately $50 \mu \mathrm{L}$ ) was collected after centrifugation at $10,000 \mathrm{rpm}$ for $15 \mathrm{~min}$ at $4^{\circ} \mathrm{C}$. GLAST or IgG antibody ( $1 \mu \mathrm{L}$; CST, \#5684, Santa Cruz, sc-2025, respectively) and supernatant were co-incubated overnight at $4^{\circ} \mathrm{C}$ in a shaker. An equal volume of beads (Santa Cruz, sc-2003) were added. The mixture was incubated at room temperature for $4 \mathrm{~h}$, followed by centrifugation at 3,000 rpm for $5 \mathrm{~min}$ at $4^{\circ} \mathrm{C}$. The beads were rinsed three times with IP lysis solution, and finally resuspended in $30 \mu \mathrm{l}$ of IP lysis solution. Western Blotting was performed after adding $30 \mu \mathrm{l}$ of loading buffer to boil.

\section{Western Blot}

To extract total protein, cochleae were homogenized in radioimmunoprecipitation assay buffer (containing 1\% enzyme inhibitor), and the bones were removed. Samples were loaded according to total protein amount, which was calculated by measuring the gray level of $\beta$-actin (1:200, Santa Cruz, sc47778). Proteins were separated using sodium dodecyl sulfatepolyacrylamide gel electrophoresis. After electrophoresis, the proteins were transferred onto a nitrocellulose membrane and blocked with 5\% degreased milk powder in PBS plus $0.1 \%$ Tween 20 (PBST). The membrane was incubated with primary antibodies at $4^{\circ} \mathrm{C}$ overnight and washed three times $(10 \mathrm{~min}$ per wash) with PBST. The membranes were then incubated with the secondary antibodies for $2 \mathrm{~h}$. After the membrane was washed, the protein bands were visualized by electrochemiluminescence.

\section{Statistical Analysis}

All data are expressed as the mean \pm standard error of the mean. All statistical analyses were performed using GraphPad Prism version 8 . ABR threshold and amplitude data were analyzed by two-way analysis of variance (ANOVA). CtBP2 count and protein expression levels were analyzed by one-way ANOVA.

\section{RESULTS}

\section{ABR Threshold and Wave I Amplitude Detection}

To examine the effects of noise on the peripheral auditory system, we first compared hearing thresholds between the control and noise groups on days 1, 7, and 30-post exposure. There was no change in the $4 \mathrm{kHz}$ hearing threshold (Figure 1B). Hearing thresholds at $8 \mathrm{kHz}$ were only significantly elevated on day 1 after exposure (Figure 1C), and significantly higher than that of the control on days 1 and 7 after noise exposure, at both $12 \mathrm{kHz}$ and $16 \mathrm{kHz}$ (Figures 1A,D,E). The thresholds of all pure tones were not significantly different from controls on day 30 post-exposure (Figures 1A-E). These ABR threshold results indicate that the TTS is caused by noise. Furthermore, hair cell damage was not detected on days 1, 7, or 30 after noise exposure, compared to the Ctr (Figure 1F).

We then measured the change in wave I amplitude and found that the wave I amplitude of all pure tones was significantly lower than that of the Ctr (Figures 2A-E). On day 1 after noise exposure, the amplitude of wave I was the lowest at all frequencies (Figures 2B-E). On day 7, the amplitude recovered compared to day 1 (Figures $\mathbf{2 B}-\mathbf{E}$ ). On day 30, there was a significant decrease in amplitude compared with the Ctr, as well as a decrease compared to day 7 (Figures 2B-E). These amplitude results indicate that nerve transmission was damaged by noise exposure. It seems that the latency of wave I was delayed after noise exposure (Figure 2A). Through statistical analysis, no significant difference was found in latency of wave I on day 30 (data not show), which is consistent with previous studies (Kujawa and Liberman, 2015; Liberman et al., 2015; Fernandez et al., 2020; Kohrman et al., 2020; Wei et al., 2020; Song et al., 2021).

\section{Ribbon Synaptopathy Caused by Noise Exposure}

Since the amplitude of ABR wave I indicates the total activity of the SGN (Plack et al., 2016), we stained for CtBP2 on day 1,7 , and 30 after noise exposure, to determine whether the decrease in wave I amplitude was caused by ribbon synaptopathy. Punctate CtBP2 was distributed around IHCs as well as within the nuclei, and in supporting cells (Figure 3A). In the apical region, $\mathrm{CtBP} 2$ numbers decreased significantly on day 1 after noise exposure; however, $\mathrm{CtBP} 2$ numbers recovered significantly on days 7 and 30, but this difference was not significant compared to that of day 1 (Figures 3A,B). In the middle region, the number 

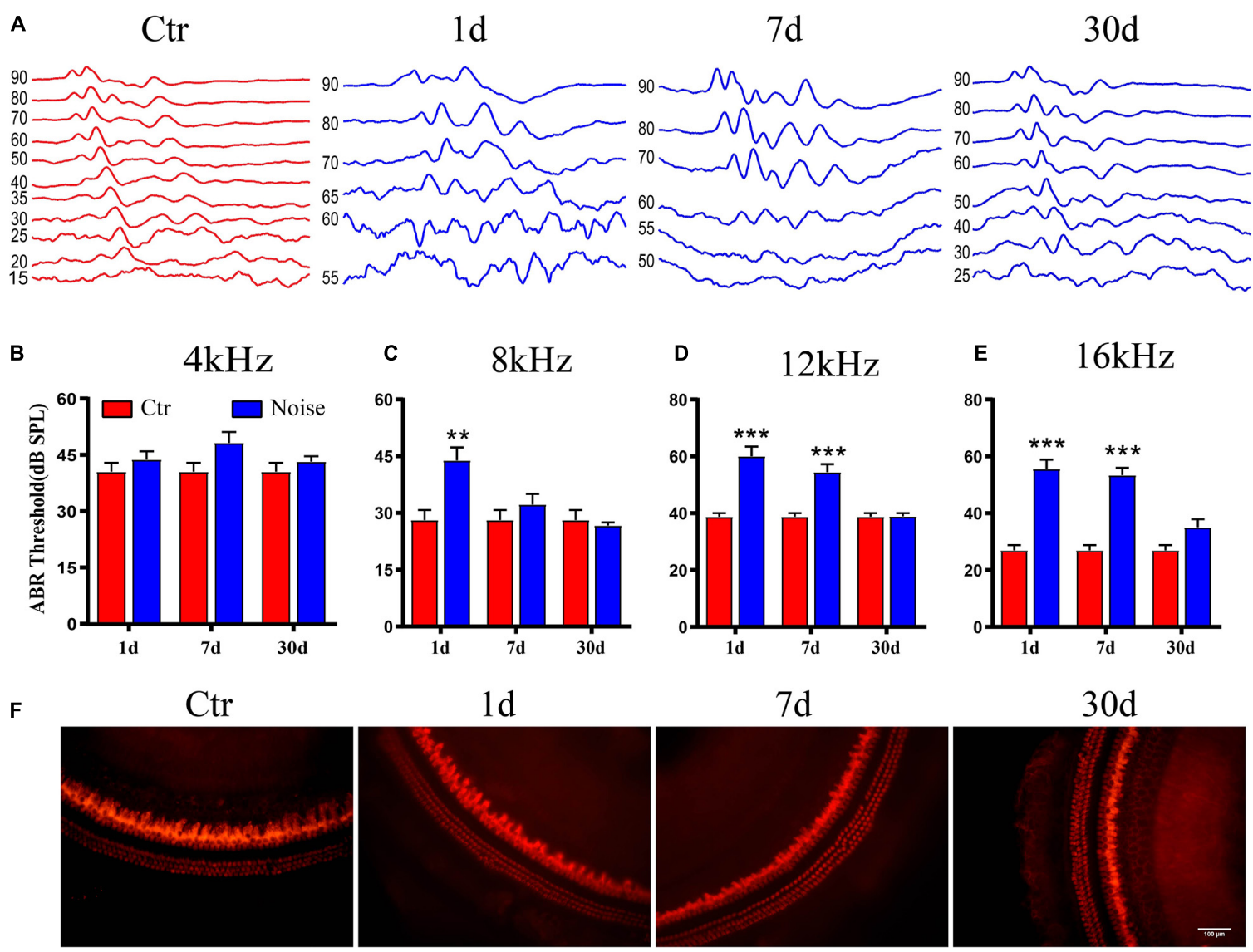

FIGURE 1 | Auditory brainstem response (ABR) threshold following noise exposure. (A) The waveform of control and day 1, 7, and 30 after noise exposure with $90 \mathrm{~dB}$ SPL pure tone stimulation at $16 \mathrm{kHz}$. (B-E) Statistical analysis of ABR threshold showed temporary threshold shift at $4 \mathrm{kHz}$ (B), $8 \mathrm{kHz}$ (C), $12 \mathrm{kHz}$ (D), and $16 \mathrm{kHz}$ (E) ( $n=9-10)$. (F) Immunofluorescence image of hair cells at middle turn in the basilar membrane with anti-myosin Vlla antibody at 20x objective, scale bar $=100 \mu \mathrm{m} .{ }^{* *}$ vs. Ctr, $p<0.01 ;{ }^{* * *}$ vs. Ctr, $p<0.001$.

of CtBP2 decreased on day 1 after noise exposure, but there was no significant difference compared with the Ctr. On day 7 after exposure, the numbers were equivalent to controls and recovered compared with day 1 after noise exposure. The CtBP2 numbers were significantly lower than those in the Ctr on day 30, after noise exposure (Figures 3A,C). In the apical and middle regions, the recovery of $\mathrm{CtBP} 2$ may suggest the presence of synaptic remodeling. In the base region, the number of CtBP2 decreased significantly on days 1,7 , and 30 after noise exposure (Figures 3A,D). The change in CtBP2 numbers is consistent with the change in wave I amplitude.

\section{The Interaction of GLAST and $\mathrm{Na}^{+} / \mathrm{K}^{+}$-ATPase $\alpha 1$ in Cochlea}

Studies of the CNS have shown a clear interaction between GLAST and $\mathrm{Na}^{+} / \mathrm{K}^{+}$-ATPase $\alpha 1$ (Bauer et al., 2012; Zhang et al., 2016). To investigate the relationship between GLAST and $\mathrm{Na}^{+} / \mathrm{K}^{+}$-ATPase $\alpha 1$ in the cochlea, we performed immunoprecipitation and immuno co-localization within the cochlea. After purification of the protein with GLAST antibody, immunoblotting of GLAST and $\mathrm{Na}^{+} / \mathrm{K}^{+}$-ATPase $\alpha 1$ on the same membrane was performed sequentially, and clear bands were observed in the input lane and the GLAST lane, but not in the IgG lane (Figure 4A). Following, we detected immunoreactivity of GLAST and $\mathrm{Na}^{+} / \mathrm{K}^{+}$-ATPase $\alpha 1$ in the cochlear basilar membrane; only GLAST immuno-positivity was identified (Figure 4B). To determine immunoreactivity in other structures, we performed immunofluorescence using frozen sections. We found co-localization of GLAST and $\mathrm{Na}^{+} / \mathrm{K}^{+}$ATPase $\alpha 1$ in the stria vascularis (Figure 4C, white dovetailed arrowhead, D), the spiral ligament (Figure 4C, white flat-tailed arrowhead, D), and spiral ganglion cells (Figures 4C,D). $\mathrm{Na}^{+} / \mathrm{K}^{+}$-ATPase $\alpha 1$ was only expressed in hair cells in the Organ of Cotti. There is no evidence that GLAST and $\mathrm{Na}^{+} / \mathrm{K}^{+}$-ATPase $\alpha 1$ are co-expressed in PCs which are major cells to take in glutamate (Figures 4B-D).

\section{Noise Exposure Disorders Vglut3, GLAST and $\mathrm{Na}^{+} / \mathrm{K}^{+}$-ATPase $\alpha 1$ Expression}

To determine the changes in Vglut3, GLAST or $\mathrm{Na}^{+} / \mathrm{K}^{+}$-ATPase $\alpha 1$, we examined the expression levels of these proteins at $2 \mathrm{~h}, 1$ day, 7 days, and 30 days after noise exposure (Figure 5A). Vglut3 

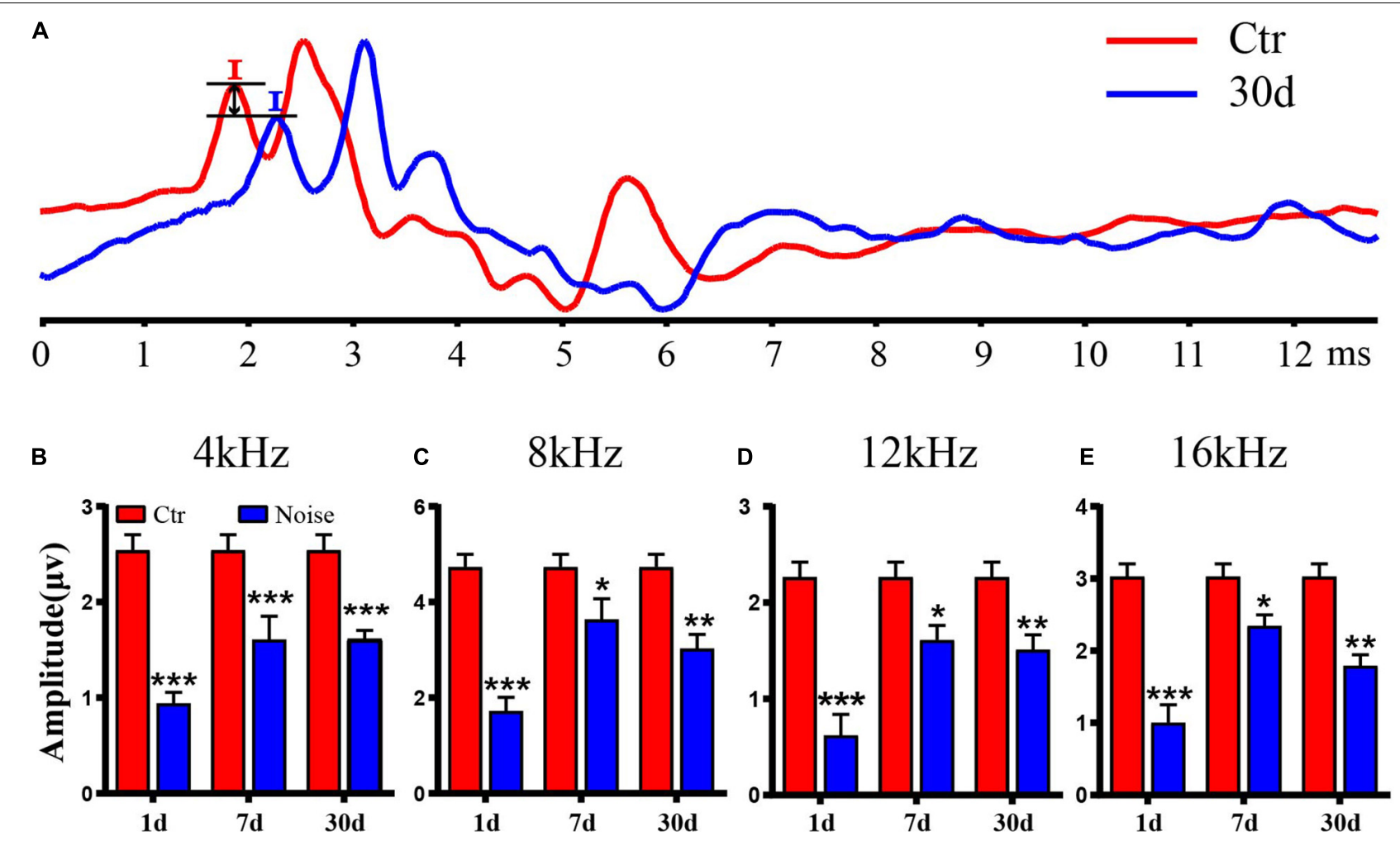

FIGURE 2 | Auditory brainstem response (ABR) wave I amplitude after noise exposure. (A) The comparison of wave I amplitude of the control group and day 30 after noise exposure with $90 \mathrm{~dB}$ SPL pure tone stimulation at $16 \mathrm{kHz}$. (B-E) Statistical analysis of wave I amplitude at $4 \mathrm{kHz}$ (B), $8 \mathrm{kHz}$ (C), $12 \mathrm{kHz}$ (D), and $16 \mathrm{kHz}$ (E) $(n=9-10) .{ }^{*}$ vs. Ctr, $p<0.05 ;{ }^{\star *}$ vs. Ctr, $p<0.01 ;{ }^{* * *}$ vs. Ctr, $p<0.001$.

expression level was lowest at $2 \mathrm{~h}$ after noise exposure. Vglut3 expression level recovered on day 1 , but it was still lower than that of the Ctr. On day 7, the Vglut3 expression level increased significantly compared to that of the control at hour 2 or day 1 (Figure 5B). Vglut3 expression level decreased on day 30 but was still significantly higher than that in the control at hour 2, or day 1 (Figure 5B). The expression levels of GLAST and $\mathrm{Na}^{+} / \mathrm{K}^{+}$-ATPase $\alpha 1$ were completely opposite to those of Vglut3. The expression level of GLAST gradually increased between hour 2 and day 7, it recovered until on day 30 after noise exposure (Figure 5C). The change in $\mathrm{Na}^{+} / \mathrm{K}^{+}$-ATPase $\alpha 1$ was consistent with GLAST at $2 \mathrm{~h}$ and 1 day after noise exposure, but returned to normal levels on day 7 after noise exposure, and significantly decreased on day 30 compared to day 1 (Figure 5D). These results indicate an enhanced ability to release glutamate and a decreased ability to uptake glutamate on day 30 after noise exposure, which may be the main mediator of synaptopathy.

\section{DISCUSSION}

The cochlear hair cells are sensitive to aging, acoustic trauma, ototoxic drugs, and environmental or genetic influences (Zhu et al., 2018; Fang et al., 2019; He et al., 2020; Jiang et al., 2020; Qian et al., 2020; Lv et al., 2021; Zhang et al., 2021). Previous reports have shown that oxidative stress and cell apoptosis play important roles in noise induced hair cell loss and ribbon synaptopathy (Sun et al., 2014; Yu et al., 2017; Li et al., 2018; Gao et al., 2019; He et al., 2019; Zhang Y. et al., 2019; Zhong et al., 2020). In this study, we confirmed the interaction between GLAST and $\mathrm{Na}^{+} / \mathrm{K}^{+}$ATPase $\alpha 1$ in the cochlea of C57BL/6J mice; protein expression was mainly co-localized in the stria vascularis, spiral ligament, and spiral ganglion cells, but not in the PCs, the major site of glutamate uptake. On day 30 after noise exposure, C57BL/6J mice experienced a TTS, a decrease in wave I amplitude at the 4, 8, 12 , and $16 \mathrm{kHz}$ cochlear regions, and a decrease in the amount of the presynaptic protein CtBP2. Meanwhile, the expression level of Vglut3 was upregulated on day 30 after exposure, and the expression level of GLAST remained almost unchanged, however, the expression level of $\mathrm{Na}^{+} / \mathrm{K}^{+}$-ATPase $\alpha 1$, which is directly coupled to GLAST, was downregulated. These findings may reveal an intrinsic link between noise-induced glutamate excitotoxicity and ribbon synaptopathy.

Vglut3 dysfunction or deficiency disrupts nerve conduction in the peripheral auditory system. LSP5-2157, an inhibitor of Vglut3, inhibited the compound action potential of the peripheral auditory system in guinea pigs (Poirel et al., 2020). Animals lose hearing after knockout of the Vglut3 allele; however, it can be restored using an adenoviral vector delivery system to re-establish Vglut3 expression (Akil et al., 2015; Akil and Lustig, 2019; Kim et al., 2019). In our study, the expression of Vglut3 was lowest at $2 \mathrm{~h}$, slightly recovered on day 1 , was highest on day 7 , and 

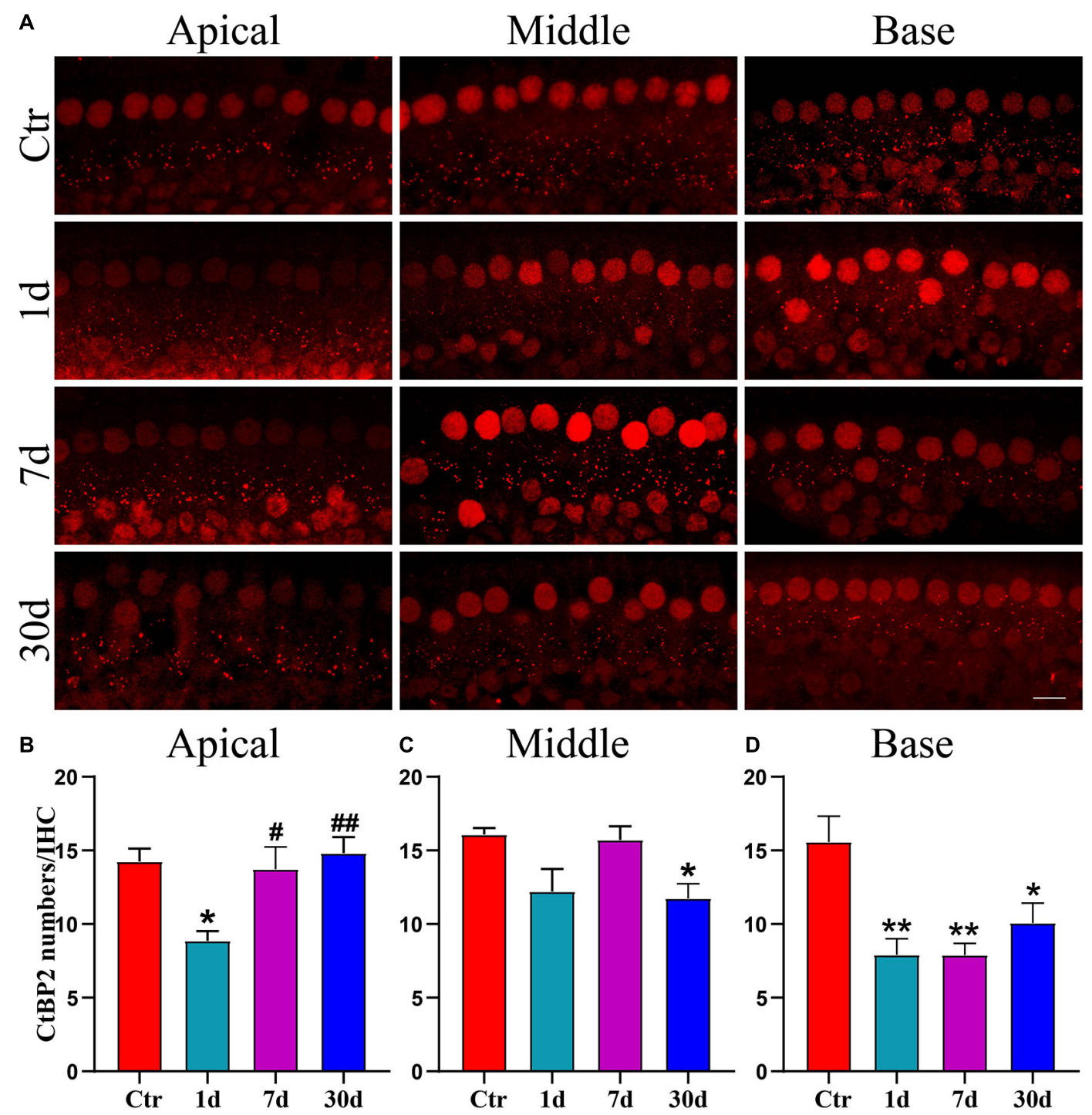

FIGURE 3 | Changes of CtBP2 numbers after noise exposure. (A) Immunofluorescence images was taken by confocal microscope with a 63x oil objective. Punctate CtBP2 was labeled with a CtBP2 antibody in IHCs; IHCs and supporting cells' nuclei were also stained, scale bars = $10 \mu \mathrm{m}$. (B-D) Statistical analysis of CtBP2 in each group ( $n=4-5$ ears) on day 1 , day 7 , and day 30 after noise exposure. *vs. Ctr, $p<0.05$; ${ }^{\star *}$ vs. Ctr, $p<0.01$; \#vs. 1 day, $p<0.05$; \#\#vs. 1 day, $p<0.01$.

slightly lowered on day 30 which was almost consistent with the observed change in wave I amplitude. Hu et al. (2020) and Sebe et al. (2017) considered that noise-induced ribbon synaptopathy is caused by over-activation of $\mathrm{Ca}^{2+}$-permeable AMPA receptors (CP-AMPARs), which lack GluR2, and mediate excessive inward $\mathrm{Ca}^{2+}$ which can damage presynaptic ribbons and postsynaptic receptors. Kim et al. (2019) revealed the role of the Vglut3 in CPAMPAR-mediated glutamatergic excitotoxicity. They found that a single copy of the Vglut3 gene was sufficient to cause ribbon synaptopathy after noise exposure, and deletion of the Vglut3 allele reduced excitotoxicity induced by noise. Our study found that the intensity of CtBP2 significantly reduced in the apical and base regions on day 1 after noise exposure, compared to that of the Ctr, and that the expression of CtBP2 in the middle region was reduced compared to the Ctr (not statistically significant).
Although Vglut3 expression levels decreased on day 1 after noise exposure, the ribbon synapse structure was also damaged, which means that low levels of glutamate can also cause ribbon synaptopathy under the influence of noise. Synapses recovered on day 7 (apical and middle region) or day 30 (apical region) after exposure, suggesting the presence of synaptic reconstruction. ABR thresholds and wave I amplitudes of Vglut $3^{\mathrm{WT}}$ animals recovered better than Vglut3 ${ }^{+/-}$mice exposed to $94 \mathrm{~dB}$ SPL noise, indicating that Vglut3 or glutamate release contributed to hearing recovery (Kim et al., 2019). Glutamate release may also help to construct synapses (Akil et al., 2012; Shi et al., 2013; Song et al., 2021). Synaptic remodeling was not observed on day 7 in the base region, and it is possible that the base region is more susceptible to noise and the development of ribbon synaptopathy. Our results are consistent with those of the previous studies. 
A

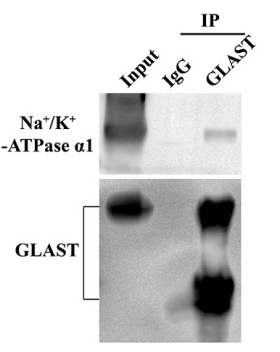

C

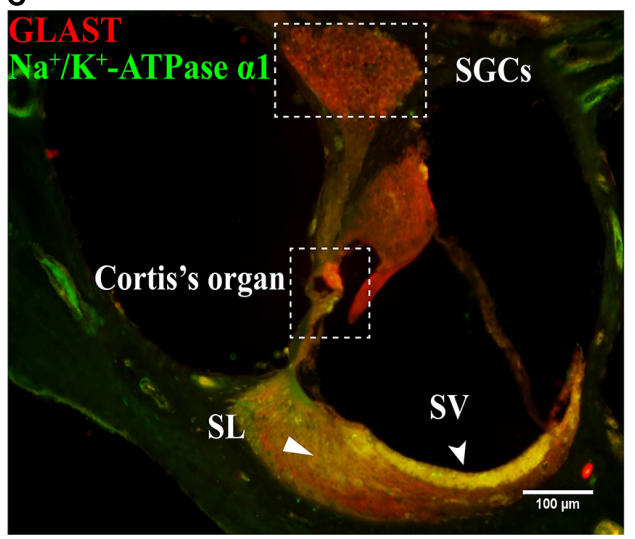

B GLAST
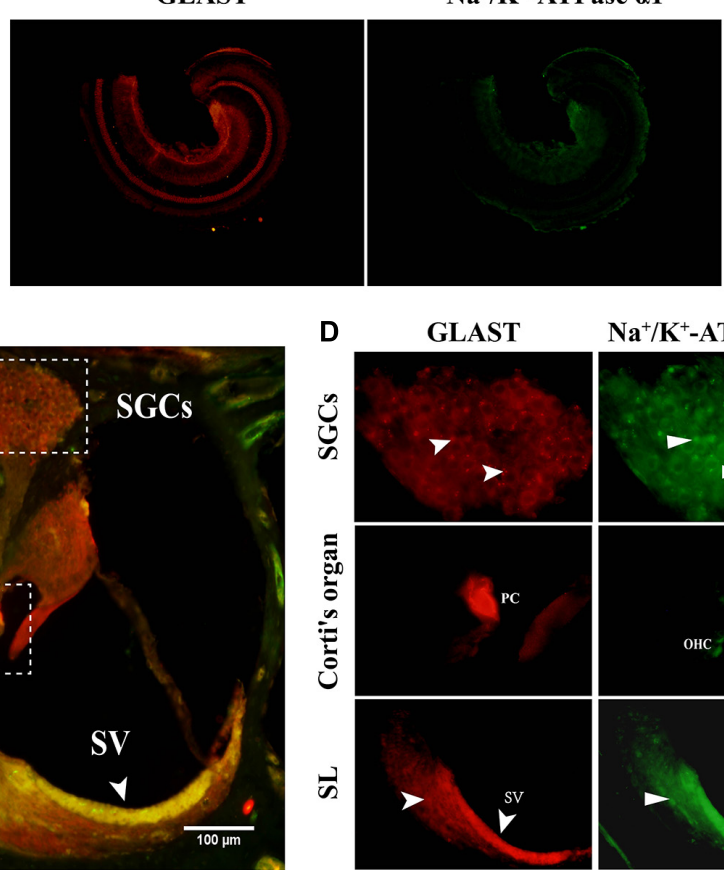

$\mathrm{Na}^{+} / \mathrm{K}^{+}$-ATPase $\alpha 1$

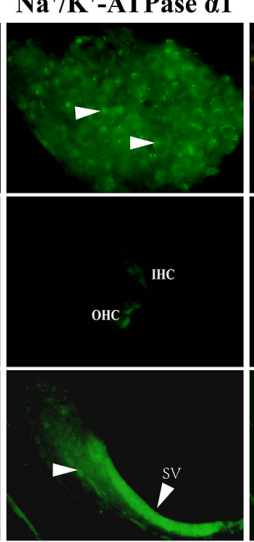

Merge

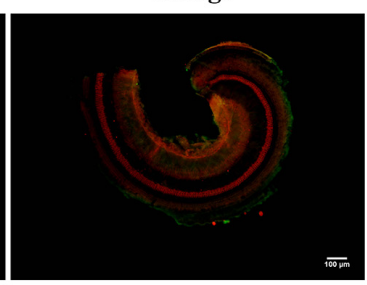

$\overline{100 \mathrm{~mm}}$

FIGURE 4 | Interaction of GLAST and $\mathrm{Na}^{+} / \mathrm{K}^{+}$-ATPase $\alpha 1$. (A) Immunoprecipitation of GLAST from cochlear tissue. Anti-GLAST antibody or IgG was used for Immunoprecipitation from cochlea lysates ( $n=10$ ears). Except for the lgG lane, endogenous $\mathrm{Na}^{+} / \mathrm{K}^{+}$-ATPase $\alpha 1$ and $\mathrm{GLAST}$ were all detected on the same membrane. (B) Immunofluorescence image of apical turn in the basilar membrane, scale bar = $100 \mu \mathrm{m}$. (C) Frozen sections of noise-unexposed C57BL/6J cochlea were stained with anti-GLAST antibody (red) and anti- $\mathrm{Na}^{+} / \mathrm{K}^{+}$-ATPase $\alpha 1$ (green) antibody, scale bar = $100 \mu \mathrm{m}$; the dovetailed arrowhead represents SV; the flat-tailed arrowhead represents SL. (D) Corti's organ and spiral ganglion cells (SGCs) were magnified under 100x oil objective, scale bars = $20 \mu \mathrm{m}$; spiral ligament is magnified under 40x objective, scale bars = $50 \mu \mathrm{m}$; GLAST (the dovetailed arrowhead), $\mathrm{Na}^{+} / \mathrm{K}^{+}$-ATPase $\alpha 1$ (the flat-tailed arrowhead) and merged immunopositive fluorescence (the arrow) were point out in particular. SGCs, spiral ganglion cells; SV, stria vascularis; SL, spiral ligament; PCs, pillar cells; OHCs, out hair cells; IHCs, inner hair cells.

Reduced ribbon synapses may promote the expression of Vglut3 protein to maintain physiological signal transduction.

The main function of GLAST transport extracellular glutamate, while the uptake drive depends on the $\mathrm{Na}^{+}$ concentration gradient inside and outside of cells; $\mathrm{Na}^{+} / \mathrm{K}^{+}$ATPase maintains the $\mathrm{Na}^{+}$gradient concentration difference by hydrolyzing ATP (Robinson and Jackson, 2016). Studies on astrocytes and the CNS have shown that $\mathrm{Na}^{+} / \mathrm{K}^{+}$-ATPase is directly coupled to GLAST via the $\alpha$ subunit (Rose et al., 2009; Bauer et al., 2012; Robinson and Jackson, 2016; Zhang et al., 2016). In the peripheral auditory system, GLAST and $\mathrm{Na}^{+} / \mathrm{K}^{+}$-ATPase $\alpha 1$ are both expressed in PCs surrounding IHCs (Glowatzki et al., 2006; McLean et al., 2009; Sundaresan et al., 2016; Liu W. et al., 2019a; Stephenson et al., 2021). In our study, we found an interaction between GLAST and $\mathrm{Na}^{+} / \mathrm{K}^{+}$-ATPase $\alpha 1$; however, immuno co-localization revealed that the sites of interaction were in the stria vascularis, spiral ligament, and SGCs. There was no $\alpha 1$ subunit immunoreactivity in the PCs. Immunoreactivity of $\mathrm{Na}^{+} / \mathrm{K}^{+}$-ATPase $\alpha 1$ have been demonstrated in stria vascularis, spiral ligament and support cells in the human cochlea (Stephenson et al., 2021). Our findings on $\mathrm{Na}^{+} / \mathrm{K}^{+}$-ATPase $\alpha 1$ were consistent with published researches on stria vascularis, spiral ligament, SGCs and hair cells (Clemens Grisham et al., 2013; Yamaguchi et al., 2014;
Ding et al., 2018; Liu W. et al., 2019a; Stephenson et al., 2021). Our findings in PCs differ from studies done in rats (McLean et al., 2009). PCs and IHCs are adjacent in spatial structure, which maybe an account for no immunoreactivity of $\mathrm{Na}^{+} / \mathrm{K}^{+}$-ATPase $\alpha 1$ in PCs. $\mathrm{Na}^{+} / \mathrm{K}^{+}$-ATPase $\alpha 1$ not expressing simultaneously in PCs or IHCs can reduce structural and functional redundancy.

The functional deficiency of GLAST affects hearing sensitivity and synaptic integrity (Yu et al., 2016; Tserga et al., 2020b). Glutamate levels in the endolymph fluid were twice as high in GLAST knockout animals compared to wild-type mice, after noise exposure, revealing that noise-induced hearing loss and ribbon synaptopathy may be caused by glutamate excitotoxicity (Hakuba et al., 2000). The combined exogenous inhibitor and glutamate perfusion further demonstrated the importance of GLAST in the hearing system (Chen et al., 2010). In our study, GLAST expression levels gradually increased after noise exposure and recovered on day 30, possibly indicating that the inner ear prevented glutamate toxicity by increasing GLAST expression levels. However, Vglut3 expression level increased on day 7 , thereby increasing the release of glutamate. The extent of GLAST increase may not be sufficient to fully take in glutamate due to increased Vglut3 expression level, resulting in excitotoxicity. Aminoglycosides, 

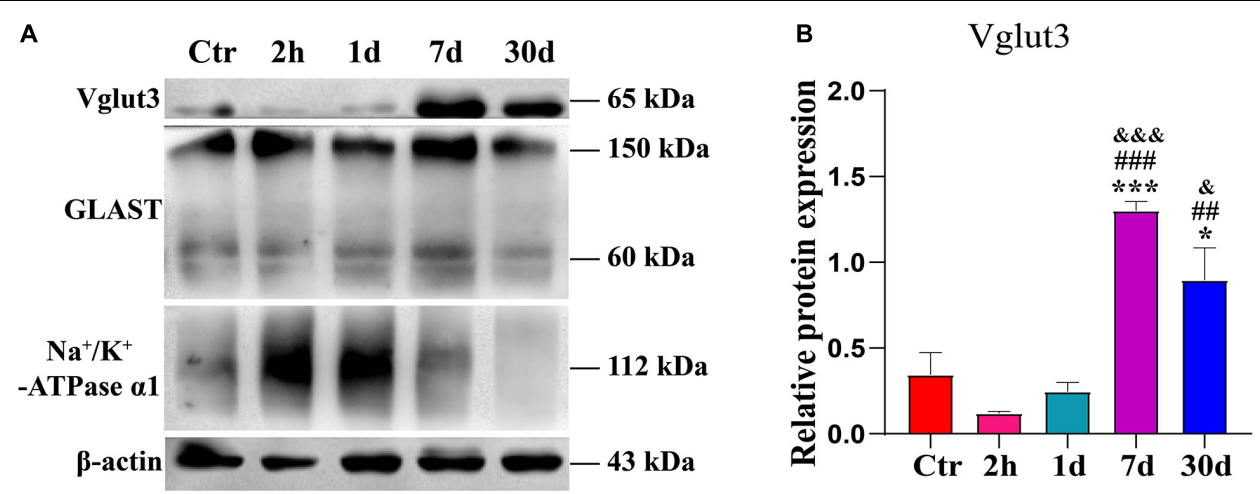

C

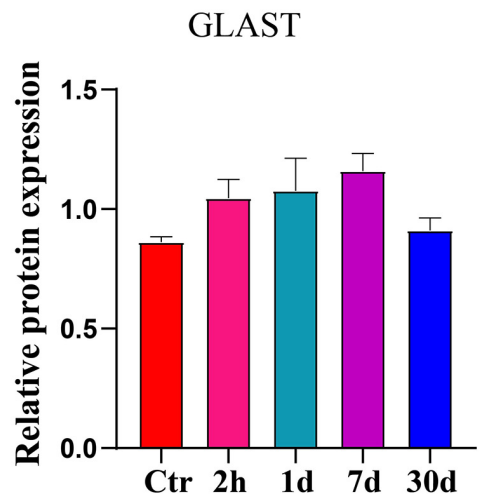

D $\quad \mathrm{Na}^{+} / \mathrm{K}^{+}$-ATPase $\alpha 1$

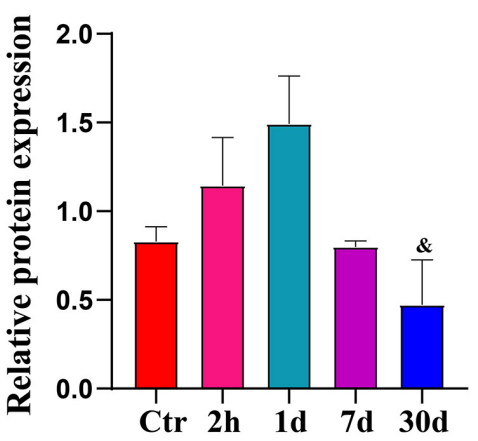

FIGURE 5 | Expression levels of GLAST, Na+/K+-ATPase $\alpha 1$ and Vglut3 were disrupted after noise exposure. (A) Western blot of Vglut3, GLAST and $\mathrm{Na}^{+} / \mathrm{K}^{+}$-ATPase $\alpha 1$ from normal cochlea and noise-exposure cochlea on hour 2, day 1, day 7, day 30 after noise ( $n=6-8$ ears). (B-D) Quantification of expression

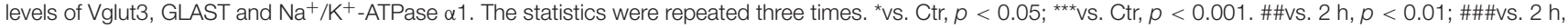
$p<0.001 ;$ \&vs. 1 day, $p<0.05 ; \& \& \&$ vs. 1 day, $p<0.001$.

like noise, are excitotoxic to the peripheral auditory system (Kohrman et al., 2020). Kanamycin, an aminoglycoside, induced high expression of cochlear GLAST mRNA, which returned to normal until the 12th day after treatment (Matsuda et al., 1999). Although there is no significantly difference in expression of GLAST in our study, we found that there is the tendency for decreasing of excitotoxicity through increasing of GLAST. In our study, the expression pattern of GLAST induced by noise was consistent with that of kanamycin (Matsuda et al., 1999).

The interaction of $\mathrm{Na}^{+} / \mathrm{K}^{+}$-ATPase $\alpha 1$ with GLAST determines its important role in glutamate uptake. Ouabain, a selective inhibitor of $\mathrm{Na}^{+} / \mathrm{K}^{+}$-ATPase, can cause pathological changes in the rodent cochlea, mainly type I SGN damage (Lang et al., 2005; Fu et al., 2012; Yuan et al., 2014; Zhang et al., 2017; Schomann et al., 2018). Low spontaneous rate fiber damage in type I fibers is an important feature of synaptopathy (Furman et al., 2013; Kujawa and Liberman, 2015). Inhibition of $\mathrm{Na}^{+} / \mathrm{K}^{+}$-ATPase activity may significantly reduce the ability of GLAST to take-up glutamate (Rose et al., 2009). In our study, we found that the expression of GLAST and $\mathrm{Na}^{+} / \mathrm{K}^{+}$-ATPase $\alpha 1$ were almost identical within a week after noise exposure, which is reasonable for reducing excitotoxicity. The expression level of $\mathrm{Na}^{+} / \mathrm{K}^{+}$-ATPase $\alpha 1$ was reduced on day 30 after noise exposure, which may limit the function of GLAST, and the expression of
Vglut3 increased, resulting in a pathological concentration of glutamate in the synaptic cleft, causing ribbon synaptopathy.

\section{SUMMARY}

In this study, we found an interaction between GLAST and $\mathrm{Na}^{+} / \mathrm{K}^{+}$-ATPase $\alpha 1$ in the cochlea of C57BL/6J mice. Based on the present results, we conclude that noise exposure influences ribbon synapses in two ways: (1) Noise briefly downregulated the expression of Vglut3 and upregulated the expression of GLAST and $\mathrm{Na}^{+} / \mathrm{K}^{+}$-ATPase $\alpha 1$, which trend to help to reduce glutamate toxicity in the synaptic cleft; (2) Noise damages ribbon synapses, and Vglut3 expression is upregulated for the normal transmission of auditory signals, but further downregulation of $\mathrm{Na}^{+} / \mathrm{K}^{+}$-ATPase $\alpha 1$ limits the uptake function of GLAST on day 30 , which may further increase glutamate toxicity. Our study may provide a new approach for the prevention and treatment of ribbon synaptopathy.

\section{DATA AVAILABILITY STATEMENT}

The original contributions presented in the study are included in the article/supplementary material, further inquiries can be directed to the corresponding author/s. 


\section{ETHICS STATEMENT}

The animal study was reviewed and approved by Laboratory Animal Welfare Ethics Committee of Tianjin Institute of Environmental and Operational Medicine.

\section{AUTHOR CONTRIBUTIONS}

$\mathrm{KM}$ and $\mathrm{AZ}$ performed whole experimental work. $\mathrm{KM}$ wrote the manuscript. XS contributed to ABR experiment. XS, HY, KW, and $\mathrm{YZ}$ contributed to data analysis. $\mathrm{HY}, \mathrm{XG}$, and $\mathrm{BC}$ contributed

\section{REFERENCES}

Akil, O., and Lustig, L. (2019). AAV-Mediated Gene Delivery to the Inner Ear. Methods Mol. Biol. 1950, 271-282. doi: 10.1007/978-1-4939-9139-6_16

Akil, O., Rouse, S. L., Chan, D. K., and Lustig, L. R. (2015). Surgical method for virally mediated gene delivery to the mouse inner ear through the round window membrane. J. Vis. Exp. 97:e52187. doi: 10.3791/52187

Akil, O., Seal, R. P., Burke, K., Wang, C., Alemi, A., During, M., et al. (2012). Restoration of hearing in the VGLUT3 knockout mouse using virally mediated gene therapy. Neuron 75, 283-293. doi: 10.1016/j.neuron.2012.05.019

Bakay, W. M. H., Anderson, L. A., Garcia-Lazaro, J. A., McAlpine, D., and Schaette, R. (2018). Hidden hearing loss selectively impairs neural adaptation to loud sound environments. Nat. Commun. 9:4298. doi: 10.1038/s41467-018-06777-y

Bauer, D. E., Jackson, J. G., Genda, E. N., Montoya, M. M., Yudkoff, M., and Robinson, M. B. (2012). The glutamate transporter, GLAST, participates in a macromolecular complex that supports glutamate metabolism. Neurochem. Int. 61, 566-574. doi: 10.1016/j.neuint.2012.01.013

Chen, Y., Gu, Y., Li, Y., Li, G. L., Chai, R., Li, W., et al. (2021). Generation of mature and functional hair cells by co-expression of Gfil, Pou4f3, and Atoh1 in the postnatal mouse cochlea. Cell Rep. 35:109016. doi: 10.1016/j.celrep.2021. 109016

Chen, Z., Kujawa, S. G., and Sewell, W. F. (2010). Functional roles of high-affinity glutamate transporters in cochlear afferent synaptic transmission in the mouse. J. Neurophysiol. 103, 2581-2586. doi: 10.1152/jn.00018.2010

Cheng, C., Hou, Y., Zhang, Z., Wang, Y., Lu, L., Zhang, L., et al. (2021). Disruption of the autism-related gene Pak1 causes stereocilia disorganization, hair cell loss, and deafness in mice. J. Genet. Genomics [Epub Online ahead of print]. doi: 10.1016/j.jgg.2021.03.010

Cheng, C., Wang, Y., Guo, L., Lu, X., Zhu, W., Muhammad, W., et al. (2019). Agerelated transcriptome changes in Sox2+ supporting cells in the mouse cochlea Stem Cell Res. Ther. 10:365. doi: 10.1186/s13287-019-1437-0

Clemens Grisham, R., Kindt, K., Finger-Baier, K., Schmid, B., and Nicolson, T. (2013). Mutations in ap $1 b 1$ cause mistargeting of the $\mathrm{Na}^{+} / \mathrm{K}^{+}$-ATPase pump in sensory hair cells. PloS One, 8:e60866. doi: 10.1371/journal.pone.0060866

Ding, B., Walton, J. P., Zhu, X., and Frisina, R. D. (2018). Age-related changes in $\mathrm{Na}$, K-ATPase expression, subunit isoform selection and assembly in the stria vascularis lateral wall of mouse cochlea. Hear. Res. 367, 59-73. doi: 10.1016/j. heares.2018.07.006

Fang, Q., Zhang, Y., Da, P., Shao, B., Pan, H., He, Z., et al. (2019). Deletion of Limk1 and Limk2 in mice does not alter cochlear development or auditory function. Sci. Rep. 9:3357. doi: 10.1038/s41598-019-39769-z

Fernandez, K. A., Guo, D., Micucci, S., De Gruttola, V., Liberman, M. C., and Kujawa, S. G. (2020). Noise-induced Cochlear Synaptopathy with and Without Sensory Cell Loss. Neuroscience 427, 43-57. doi: 10.1016/j.neuroscience.2019. 11.051

Fu, X., An, Y., Wang, H., Li, P., Lin, J., Yuan, J., et al. (2021). Deficiency of Klc2 Induces Low-Frequency Sensorineural Hearing Loss in C57BL/6 J Mice and Human. Mol. Neurobiol. [Epub Online ahead of print]. doi: 10.1007/s12035021-02422-w

Fu, Y., Ding, D., Jiang, H., and Salvi, R. (2012). Ouabain-induced cochlear degeneration in rat. Neurotox. Res. 22, 158-169. doi: 10.1007/s12640-0129320-0 to the experimental design. $\mathrm{XG}$ and $\mathrm{BC}$ revised the manuscript. $\mathrm{KM}$ and $\mathrm{BC}$ secured funding for the study. All authors discussed the results and approved the final manuscript.

\section{FUNDING}

This work was supported by the Innovation Funding of Tianjin Institute of Environmental and Operational Medicine (HZ18R03) and the Special Project on Innovation and Generation of Medical Support Capability (2018CXJJ05 and 20WQ042).

Furman, A. C., Kujawa, S. G., and Liberman, M. C. (2013). Noise-induced cochlear neuropathy is selective for fibers with low spontaneous rates. J. Neurophysiol. 110, 577-586. doi: 10.1152/jn.00164.2013

Gao, S., Cheng, C., Wang, M., Jiang, P., Zhang, L., Wang, Y., et al. (2019). Blebbistatin Inhibits Neomycin-Induced Apoptosis in Hair Cell-Like HEI-OC 1 Cells and in Cochlear Hair Cells. Front. Cell Neurosci. 13:590. doi: 10.3389/ fncel.2019.00590

Glowatzki, E., Cheng, N., Hiel, H., Yi, E., Tanaka, K., and Ellis-Davies, G. C. (2006). The glutamate-aspartate transporter GLAST mediates glutamate uptake at inner hair cell afferent synapses in the mammalian cochlea. J. Neurosci. 26, 7659-7664. doi: 10.1523/jneurosci.1545-06.2006

Guo, R., Li, J., Chen, C., Xiao, M., Liao, M., Hu, Y., et al. (2021). Biomimetic 3D bacterial cellulose-graphene foam hybrid scaffold regulates neural stem cell proliferation and differentiation. Colloids Surf. B Biointerfaces 200:111590. doi: 10.1016/j.colsurfb.2021.111590

Guo, R., Ma, X., Liao, M., Liu, Y., Hu, Y., Qian, X., et al. (2019). Development and Application of Cochlear Implant-Based Electric-Acoustic Stimulation of Spiral Ganglion Neurons. ACS Biomater. Sci. Eng. 5, 6735-6741. doi: 10.1021/ acsbiomaterials.9b01265

Guo, R., Xiao, M., Zhao, W., Zhou, S., Hu, Y., Liao, M., et al. (2020). 2D $\mathrm{Ti}_{3} \mathrm{C}_{2} \mathrm{~T}_{\mathrm{X}} \mathrm{MXene}$ couples electrical stimulation to promote proliferation and neural differentiation of neural stem cells. Acta Biomater. [Epub Online ahead of print]. doi: 10.1016/j.actbio.2020.12.035

Guo, R., Zhang, S., Xiao, M., Qian, F., He, Z., Li, D., et al. (2016). Accelerating bioelectric functional development of neural stem cells by graphene coupling: implications for neural interfacing with conductive materials. Biomaterials 106, 193-204. doi: 10.1016/j.biomaterials.2016.08.019

Hakuba, N., Koga, K., Gyo, K., Usami, S. I., and Tanaka, K. (2000). Exacerbation of noise-induced hearing loss in mice lacking the glutamate transporter GLAST. J. Neurosci. 20, 8750-8753. doi: 10.1523/jneurosci.20-23-08750.2000

He, Z., Fang, Q., Li, H., Shao, B., Zhang, Y., Zhang, Y., et al. (2019). The role of FOXG1 in the postnatal development and survival of mouse cochlear hair cells. Neuropharmacology 144, 43-57. doi: 10.1016/j.neuropharm. 2018.10.021

He, Z., Guo, L., Shu, Y., Fang, Q., Zhou, H., Liu, Y., et al. (2017). Autophagy protects auditory hair cells against neomycin-induced damage. Autophagy 13, 1884-1904. doi: 10.1080/15548627.2017.1359449

He, Z. H., Li, M., Fang, Q. J., Liao, F. L., Zou, S. Y., Wu, X., et al. (2021). FOXG1 promotes aging inner ear hair cell survival through activation of the autophagy pathway. Autophagy [Epub Online ahead of print]. doi: 10.1080/15548627.2021. 1916194

He, Z. H., Zou, S. Y., Li, M., Liao, F. L., Wu, X., Sun, H. Y., et al. (2020). The nuclear transcription factor FoxG1 affects the sensitivity of mimetic aging hair cells to inflammation by regulating autophagy pathways. Redox Biol. 28:101364. doi: 10.1016/j.redox.2019.101364

$\mathrm{Hu}$, N., Rutherford, M. A., and Green, S. H. (2020). Protection of cochlear synapses from noise-induced excitotoxic trauma by blockade of $\mathrm{Ca}^{2+}$-permeable AMPA receptors. Proc. Natl. Acad. Sci. U. S. A. 117, 3828-3838. doi: 10.1073/pnas. 1914247117

Jiang, P., Zhang, S., Cheng, C., Gao, S., Tang, M., Lu, L., et al. (2020). The Roles of Exosomes in Visual and Auditory Systems. Front. Bioeng. Biotechnol. 8:525. doi: $10.3389 /$ fbioe. 2020.00525 
Kim, K. X., Payne, S., Yang-Hood, A., Li, S. Z., Davis, B., Carlquist, J., et al. (2019). Vesicular Glutamatergic Transmission in Noise-Induced Loss and Repair of Cochlear Ribbon Synapses. J. Neurosci. 39, 4434-4447. doi: 10.1523/jneurosci. 2228-18.2019

Kohrman, D. C., Wan, G., Cassinotti, L., and Corfas, G. (2020). Hidden Hearing Loss: a Disorder with Multiple Etiologies and Mechanisms. Cold Spring Harb. Perspect. Med. 10:a035493. doi: 10.1101/cshperspect.a035493

Kujawa, S. G., and Liberman, M. C. (2015). Synaptopathy in the noise-exposed and aging cochlea: primary neural degeneration in acquired sensorineural hearing loss. Hear. Res. 330, 191-199. doi: 10.1016/j.heares.2015.02.009

Kurabi, A., Keithley, E. M., Housley, G. D., Ryan, A. F., and Wong, A. C. (2017). Cellular mechanisms of noise-induced hearing loss. Hear. Res. 349, 129-137. doi: 10.1016/j.heares.2016.11.013

Lang, H., Schulte, B. A., and Schmiedt, R. A. (2005). Ouabain induces apoptotic cell death in type I spiral ganglion neurons, but not type II neurons. J. Assoc. Res. Otolaryngol. 6, 63-74. doi: 10.1007/s10162-004-5021-6

Li, A., You, D., Li, W., Cui, Y., He, Y., Li, W., et al. (2018). Novel compounds protect auditory hair cells against gentamycin-induced apoptosis by maintaining the expression level of H3K4me2. Drug Deliv. 25, 1033-1043. doi: 10.1080/ 10717544.2018.1461277

Liberman, L. D., Suzuki, J., and Liberman, M. C. (2015). Dynamics of cochlear synaptopathy after acoustic overexposure. J. Assoc. Res. Otolaryngol. 16, 205219. doi: 10.1007/s10162-015-0510-3

Liu, L., Chen, Y., Qi, J., Zhang, Y., He, Y., Ni, W., et al. (2016). Wnt activation protects against neomycin-induced hair cell damage in the mouse cochlea. Cell Death Dis. 7:e2136. doi: 10.1038/cddis.2016.35

Liu, W., Luque, M., Glueckert, R., Danckwardt-Lillieström, N., Nordström, C. K., Schrott-Fischer, A., et al. (2019a). Expression of Na/K-ATPase subunits in the human cochlea: a confocal and super-resolution microscopy study with special reference to auditory nerve excitation and cochlear implantation. Ups. J. Med. Sci. 124, 168-179. doi: 10.1080/03009734.2019.1653408

Liu, W., Xu, L., Wang, X., Zhang, D., Sun, G., Wang, M., et al. (2021). PRDX1 activates autophagy via the PTEN-AKT signaling pathway to protect against cisplatin-induced spiral ganglion neuron damage. Autophagy [Epub Online ahead of print]. doi: 10.1080/15548627.2021.1905466

Liu, W., Xu, X., Fan, Z., Sun, G., Han, Y., Zhang, D., et al. (2019b). Wnt Signaling Activates TP53-Induced Glycolysis and Apoptosis Regulator and Protects Against Cisplatin-Induced Spiral Ganglion Neuron Damage in the Mouse Cochlea. Antioxid. Redox Signal. 30, 1389-1410. doi: 10.1089/ars. 2017.7288

Liu, Y., Qi, J., Chen, X., Tang, M., Chu, C., Zhu, W., et al. (2019). Critical role of spectrin in hearing development and deafness. Sci. Adv. 5:eaav7803. doi: $10.1126 /$ sciadv.aav7803

Lu, X., Sun, S., Qi, J., Li, W., Liu, L., Zhang, Y., et al. (2017). Bmil Regulates the Proliferation of Cochlear Supporting Cells Via the Canonical Wnt Signaling Pathway. Mol. Neurobiol. 54, 1326-1339. doi: 10.1007/s12035-0169686-8

Lv, J., Fu, X., Li, Y., Hong, G., Li, P., Lin, J., et al. (2021). Deletion of Kcnj16 in Mice Does Not Alter Auditory Function. Front. Cell Dev. Biol. 9:630361. doi: $10.3389 /$ fcell.2021.630361

Matsuda, K., Ueda, Y., Doi, T., Tono, T., Haruta, A., Toyama, K., et al. (1999). Increase in glutamate-aspartate transporter (GLAST) mRNA during kanamycin-induced cochlear insult in rats. Hear. Res. 133, 10-16. doi: 10.1016/ s0378-5955(99)00050-7

McLean, W. J., Smith, K. A., Glowatzki, E., and Pyott, S. J. (2009). Distribution of the Na,K-ATPase alpha subunit in the rat spiral ganglion and organ of corti. J. Assoc. Res. Otolaryngol. 10, 37-49. doi: 10.1007/s10162-008-0152-9

Obholzer, N., Wolfson, S., Trapani, J. G., Mo, W., Nechiporuk, A., BuschNentwich, E., et al. (2008). Vesicular glutamate transporter 3 is required for synaptic transmission in zebrafish hair cells. J. Neurosci. 28, 2110-2118. doi: 10.1523/jneurosci.5230-07.2008

Peng, Z., Wang, G. P., Zeng, R., Guo, J. Y., Chen, C. F., and Gong, S. S. (2013). Temporospatial expression and cellular localization of VGLUT3 in the rat cochlea. Brain Res. 1537, 100-110. doi: 10.1016/j.brainres.2013.09.019

Plack, C. J., Léger, A., Prendergast, G., Kluk, K., Guest, H., and Munro, K. J. (2016). Toward a Diagnostic Test for Hidden Hearing Loss. Trends Hear. 20, 1-9. doi: $10.1177 / 2331216516657466$
Poirel, O., Mamer, L. E., Herman, M. A., Arnulf-Kempcke, M., Kervern, M., Potier, B., et al. (2020). LSP5-2157 a new inhibitor of vesicular glutamate transporters. Neuropharmacology 164:107902. doi: 10.1016/j.neuropharm.2019.107902

Qi, J., Liu, Y., Chu, C., Chen, X., Zhu, W., Shu, Y., et al. (2019). A cytoskeleton structure revealed by super-resolution fluorescence imaging in inner ear hair cells. Cell Discov. 5:12. doi: 10.1038/s41421-018-0076-4

Qi, J., Zhang, L., Tan, F., Liu, Y., and Chai, R. (2020). Espin distribution as revealed by super-resolution microscopy of stereocilia. Am. J. Transl. Res. 12, 130-141.

Qian, F., Wang, X., Yin, Z., Xie, G., Yuan, H., Liu, D., et al. (2020). The slc4a2b gene is required for hair cell development in zebrafish. Aging 12, 18804-18821. doi: 10.18632/aging.103840

Robinson, M. B., and Jackson, J. G. (2016). Astroglial glutamate transporters coordinate excitatory signaling and brain energetics. Neurochem. Int. 98, 56-71. doi: 10.1016/j.neuint.2016.03.014

Rose, E. M., Koo, J. C., Antflick, J. E., Ahmed, S. M., Angers, S., and Hampson, D. R. (2009). Glutamate transporter coupling to Na,K-ATPase. J. Neurosci. 29, 8143-8155. doi: 10.1523/jneurosci.1081-09.2009

Ruel, J., Emery, S., Nouvian, R., Bersot, T., Amilhon, B., Van Rybroek, J. M., et al. (2008). Impairment of SLC17A8 encoding vesicular glutamate transporter3, VGLUT3, underlies nonsyndromic deafness DFNA25 and inner hair cell dysfunction in null mice. Am. J. Hum. Genet. 83, 278-292. doi: 10.1016/j.ajhg. 2008.07.008

Schomann, T., Ramekers, D., de Groot, J., van der Ploeg, C. H., Hendriksen, F. G. J., Böhringer, S., et al. (2018). Ouabain Does Not Induce Selective Spiral Ganglion Cell Degeneration in Guinea Pigs. Biomed. Res. Int. 2018:1568414. doi: 10.1155/2018/1568414

Seal, R. P., Akil, O., Yi, E., Weber, C. M., Grant, L., Yoo, J., et al. (2008). Sensorineural deafness and seizures in mice lacking vesicular glutamate transporter 3. Neuron 57, 263-275. doi: 10.1016/j.neuron.2007. 11.032

Sebe, J. Y., Cho, S., Sheets, L., Rutherford, M. A., von Gersdorff, H., and Raible, D. W. (2017). $\mathrm{Ca}^{2+}$-Permeable AMPARs Mediate Glutamatergic Transmission and Excitotoxic Damage at the Hair Cell Ribbon Synapse. J. Neurosci. 37, 6162-6175. doi: 10.1523/jneurosci.3644-16.2017

Shi, L., Liu, L., He, T., Guo, X., Yu, Z., Yin, S., et al. (2013). Ribbon synapse plasticity in the cochleae of Guinea pigs after noise-induced silent damage. PloS One, 8:e81566. doi: 10.1371/journal.pone.0081566

Song, F., Gan, B., Wang, N., Wang, Z., and Xu, A. T. (2021). Hidden hearing loss is associated with loss of ribbon synapses of cochlea inner hair cells. Biosci. Rep. 41:BSR20201637. doi: 10.1042/BSR20201637

Stephenson, R., Mangasarian, A., Ishiyama, G., Hosokawa, K., Hosokawa, S., Ishiyama, A., et al. (2021). Immunohistochemical location of $\mathrm{Na}^{+}, \mathrm{K}^{+}$-ATPase $\alpha 1$ subunit in the human inner ear. Hear. Res. 400:108113. doi: 10.1016/j.heares. 2020.108113

Sun, G., Liu, W., Fan, Z., Zhang, D., Han, Y., Xu, L., et al. (2016). The ThreeDimensional Culture System with Matrigel and Neurotrophic Factors Preserves the Structure and Function of Spiral Ganglion Neuron In Vitro. Neural Plast. 2016:4280407. doi: 10.1155/2016/4280407

Sun, S., Sun, M., Zhang, Y., Cheng, C., Waqas, M., Yu, H., et al. (2014). In vivo overexpression of X-linked inhibitor of apoptosis protein protects against neomycin-induced hair cell loss in the apical turn of the cochlea during the ototoxic-sensitive period. Front. Cell Neurosci. 8:248. doi: 10.3389/fncel.2014. 00248

Sundaresan, S., Kong, J. H., Fang, Q., Salles, F. T., Wangsawihardja, F., Ricci, A. J., et al. (2016). Thyroid hormone is required for pruning, functioning and long-term maintenance of afferent inner hair cell synapses. Eur. J. Neurosci. 43, 148-161. doi: 10.1111/ejn.13081

Tan, F., Chu, C., Qi, J., Li, W., You, D., Li, K., et al. (2019). AAV-ie enables safe and efficient gene transfer to inner ear cells. Nat. Commun. 10:3733. doi: 10.1038/s41467-019-11687-8

Tserga, E., Damberg, P., Canlon, B., and Cederroth, C. R. (2020a). Auditory synaptopathy in mice lacking the glutamate transporter GLAST and its impact on brain activity. Prog. Brain Res. 262, 245-261. doi: 10.1016/bs.pbr.2020. 04.004

Tserga, E., Moreno-Paublete, R., Sarlus, H., Björn, E., Guimaraes, E., Göritz, C., et al. (2020b). Circadian vulnerability of cisplatin-induced ototoxicity in the cochlea. FASEB J. 34, 13978-13992. doi: 10.1096/fj.202001236R 
Wang, Y., Li, J., Yao, X., Li, W., Du, H., Tang, M., et al. (2017). Loss of CIB2 Causes Profound Hearing Loss and Abolishes Mechanoelectrical Transduction in Mice. Front. Mol. Neurosci. 10:401. doi: 10.3389/fnmol.2017.00401

Wei, W., Shi, X., Xiong, W., He, L., Du, Z. D., and Qu, T. (2020). RNA-seq Profiling and Co-expression Network Analysis of Long Noncoding RNAs and mRNAs Reveal Novel Pathogenesis of Noise-induced Hidden Hearing Loss. Neuroscience 434, 120-135. doi: 10.1016/j.neuroscience.2020.03.023

Yamaguchi, T., Nagashima, R., Yoneyama, M., Shiba, T., and Ogita, K. (2014). Disruption of ion-trafficking system in the cochlear spiral ligament prior to permanent hearing loss induced by exposure to intense noise: possible involvement of 4-hydroxy-2-nonenal as a mediator of oxidative stress. PLoS One 9:e102133. doi: 10.1371/journal.pone.0102133

Yu, H., Vikhe Patil, K., Han, C., Fabella, B., Canlon, B., Someya, S., et al. (2016). GLAST Deficiency in Mice Exacerbates Gap Detection Deficits in a Model of Salicylate-Induced Tinnitus. Front. Behav. Neurosci. 10:158. doi: 10.3389/fnbeh. 2016.00158

Yu, X., Liu, W., Fan, Z., Qian, F., Zhang, D., Han, Y., et al. (2017). c-Myb knockdown increases the neomycin-induced damage to hair-cell-like HEI-OC1 cells in vitro. Sci. Rep. 7:41094. doi: 10.1038/srep41094

Yuan, Y., Shi, F., Yin, Y., Tong, M., Lang, H., Polley, D. B., et al. (2014). Ouabaininduced cochlear nerve degeneration: synaptic loss and plasticity in a mouse model of auditory neuropathy. J. Assoc. Res. Otolaryngol. 15, 31-43. doi: 10. 1007/s10162-013-0419-7

Zhang, L. N., Sun, Y. J., Wang, L. X., and Gao, Z. B. (2016). Glutamate Transporters/ $\mathrm{Na}(+), \mathrm{K}(+)$-ATPase Involving in the Neuroprotective Effect as a Potential Regulatory Target of Glutamate Uptake. Mol. Neurobiol. 53, 11241131. doi: 10.1007/s12035-014-9071-4

Zhang, S., Dong, Y., Qiang, R., Zhang, Y., Zhang, X., Chen, Y., et al. (2021). Characterization of Strip1 Expression in Mouse Cochlear Hair Cells. Front. Genet. 12:625867. doi: 10.3389/fgene.2021.625867

Zhang, S., Liu, D., Dong, Y., Zhang, Z., Zhang, Y., Zhou, H., et al. (2019). Frizzled9+ Supporting Cells Are Progenitors for the Generation of Hair Cells in the Postnatal Mouse Cochlea. Front. Mol. Neurosci. 12:184. doi: 10.3389/fnmol. 2019.00184

Zhang, S., Qiang, R., Dong, Y., Zhang, Y., Chen, Y., Zhou, H., et al. (2020). Hair cell regeneration from inner ear progenitors in the mammalian cochlea. Am. J. Stem Cells 9, 25-35.

Zhang, W., Peng, Z., Yu, S., Song, Q. L., Qu, T. F., Liu, K., et al. (2020). Exposure to sodium salicylate disrupts VGLUT3 expression in cochlear inner hair cells and contributes to tinnitus. Physiol. Res. 69, 181-190. doi: 10.33549/physiolres. 934180

Zhang, Y., Li, W., He, Z., Wang, Y., Shao, B., Cheng, C., et al. (2019). Pre-treatment With Fasudil Prevents Neomycin-Induced Hair Cell Damage by Reducing the
Accumulation of Reactive Oxygen Species. Front. Mol. Neurosci. 12:264. doi: 10.3389/fnmol.2019.00264

Zhang, Y., Zhang, S., Zhang, Z., Dong, Y., and Chai, R. (2020). Knockdown of Foxg1 in Sox9+ supporting cells increases the trans-differentiation of supporting cells into hair cells in the neonatal mouse utricle. Aging 12, 1983419851. doi: 10.18632/aging.104009

Zhang, Z. J., Guan, H. X., Yang, K., Xiao, B. K., Liao, H., Jiang, Y., et al. (2017). Dose-dependent effects of ouabain on spiral ganglion neurons and Schwann cells in mouse cochlea. Acta Otolaryngol. 137, 1017-1023. doi: 10.1080/00016489.2017.132 4217

Zhao, J., Tang, M., Cao, J., Ye, D., Guo, X., Xi, J., et al. (2019). Structurally Tunable Reduced Graphene Oxide Substrate Maintains Mouse Embryonic Stem Cell Pluripotency. Adv. Sci. 6:1802136. doi: 10.1002/advs.20180 2136

Zhong, Z., Fu, X., Li, H., Chen, J., Wang, M., Gao, S., et al. (2020). Citicoline Protects Auditory Hair Cells Against Neomycin-Induced Damage. Front. Cell Dev. Biol. 8:712. doi: 10.3389/fcell.2020.00712

Zhou, H., Qian, X., Xu, N., Zhang, S., Zhu, G., Zhang, Y., et al. (2020). Disruption of Atg7-dependent autophagy causes electromotility disturbances, outer hair cell loss, and deafness in mice. Cell Death Dis. 11:913. doi: 10.1038/s41419-02003110-8

Zhu, C., Cheng, C., Wang, Y., Muhammad, W., Liu, S., Zhu, W., et al. (2018). Loss of ARHGEF6 Causes Hair Cell Stereocilia Deficits and Hearing Loss in Mice. Front. Mol. Neurosci. 11:362. doi: 10.3389/fnmol.2018.00362

Conflict of Interest: The authors declare that the research was conducted in the absence of any commercial or financial relationships that could be construed as a potential conflict of interest.

Publisher's Note: All claims expressed in this article are solely those of the authors and do not necessarily represent those of their affiliated organizations, or those of the publisher, the editors and the reviewers. Any product that may be evaluated in this article, or claim that may be made by its manufacturer, is not guaranteed or endorsed by the publisher.

Copyright (c) $2021 \mathrm{Ma}$, Zhang, She, Yang, Wang, Zhu, Gao and Cui. This is an open-access article distributed under the terms of the Creative Commons Attribution License (CC BY). The use, distribution or reproduction in other forums is permitted, provided the original author(s) and the copyright owner(s) are credited and that the original publication in this journal is cited, in accordance with accepted academic practice. No use, distribution or reproduction is permitted which does not comply with these terms. 